\title{
Study of the Jumping Phenomenon in a Cam and Follower Mechanism
}

\author{
Ali Hasan \\ ${ }^{1}$ Mechanical Engineering Department, Faculty of Engineering \& \\ Technology, Jamia Millia Islamia, New Delhi, India
}

\begin{abstract}
The basic purpose of the present study is to help the UG/PG Students/Research Scholars/Engineers as well as Scientist to select the best combination of Cam and follower avoiding jumping phenomenon to perform the required task as per specific necessity. The study is carried out in the dynamics laboratory of the department of mechanical engineering to record the critical jumping speed with the help of experimental setup. In the first part of this study, the author perform the experiment by having the spring under compression to record the jumping speed by keeping several weights on the follower assembly. In second part of the study, the author recorded the jumping speed by compressing the spring gradually for the constant weight on the follower assembly.
\end{abstract}

KEY WORDS: CAM, FOLLOWER, JUMP.

\section{INTRODUCTION}

Cam and follower mechanism is a preferred mechanism due to its important functions of all most all the reciprocating machines used in transportation, medical, and production etc industries. A cam is a rotating or translating part of the cam follower mechanism that can transmit from one type motion to another. Actually, cam follower mechanism can be used to transmit regular to irregular motion at a very low cost that is very difficult even at higher costs by using other available sophisticated means. Mahesh R. Mali et al. suggested a lot of variety of cam and follower linkages that a designer or researcher can select based on one's requirements. Cam and follower mechanisms are also used to increase the I.C. engine efficiency by various optimization techniques. R.L. Norton and R.G.

Biosc Biotech Res Comm P-ISSN: 0974-6455 E-ISSN: 2321-4007

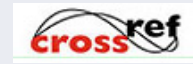

Identifiers and Pagination

Year: 2021 Vol: 14 No (5) Special Issue

Pages: $84-88$

This is an open access article under Creative

Commons License Attribn 4.0 Intl (CC-BY).

DOI: http://dx.doi.org/10.21786/bbrc/14.5/17
Mosier proposed a design for the dynamic behavior of cam and follower system and its great importance in working of I.C.Engine. J. W. David et a.l suggested an optimal and economical s design of a cam follower mechanism. The author tested this proposed economical design with the help of computer simulation and validated with the data already available in the literature. T. D. Choi et al. proposed cam follower mechanisms to achieve optimal gear train solution having lobes profile to be used in automobile industries. A. Cardona et al. suggested a cam designing technique for a gear train to be driven with the help of motor. The synthesis and analysis of a cam follower mechanism is a crucial step to achieve it economically. N.S.Patel investigated the optimal design solution for the design of a cam and follower system.

Khin Maung Chinthrows the light on motion transformation from oscillation or rotational into linear one. H. D. Desai and V. K. Patel studied the deflection in cam and follower mechanisms irrespective of its motions according to the loading conditions with the help of various computer software. Yuan L. Lai et.al suggested various failure modes in a cam and follower mechanism. A. Rivola et al. presented the various failure models in gear train and suggested the safe design using cam and follower system. 
AmolAchyutrao Pande, Surendra C. Patel suggested the cam profile geometry modification for proper working and minimum failure possibilities. The authors suggested for the point contact between the cam and follower. The stresses induced in the material should be with the safe limit. Divya Pandey et.al studied about the forecast of cam follower systems life without failure. The authors presented both the satticas well as dynamic model of the cam and follower system with the help of finite element method. It was shown in the study that the working life of cam and follower mechanisms depends upon the proper design. Jevzy Zajaczkowski proposed mathematical equations for the economical and optimal design of cam follower mechanisms by considering the material elasticity of the various elements of the system. The author considered the weight of the materials used for the designing of cam follower assembly components also.

Mandal M. and Naskar, T.K. proposed the model of cam follower design for excellent performance. The author proposed computer simulation for the high performance of the system. The design of injection cams in heavy duty diesel engines is most challenging work. Lubrication has its importance in reducing friction and wear. Advancement in materials used in construction of cam and follower for reducing the weight, noise, vibrations, stresses and higher strengths along with rigidity for efficient and accurate operations is going on throughout the world since several years. Shailendra Singh, S. Sanyal presented a research considering the effect of hygrothermal atmosphere during analyzing the cam and follower system. The investigator suggested considering the hygrothermal performance at the time of dynamical testing of the materials used in the designing of the assembly. Shailendra Singh, S. Sanyal studied the hygrothermal relation with composite material used for the design of the cam follower system during the utilization in textile industries.

The authors considered various factors in the design and testing of the assembly and its curved surfaces along with the loading and unloading conditions. Hazim U. Jamali et al. suggested the lubrication system to be used in the assembly system to get better mechanism performance and optimal design system. The authors proposed a particular lubrication thickness of the lubricant and pressure distribution. Kushwaha M. presented lubrication model analysis for the contact surface between the rotating cam and follower. Toedorescu M. et al. presented the lubricating model for four cylinder engine mechanisms to achieve the higher performance. The authors gave a tribological lubricating analysis model for engine assembly including cam and follower mechanism. Nguyen M., Kim D. J. investigated the design for flexible cam profile and follower mechanisms with the help of various curved surfaces. Vela D. et al. used the available equipment and suggested the type of contact surfaces between cam and follower for getting optimum results. Wang J.et al. worked for lubrication in engine mechanisms along with cam and follower assembly.
Cuilli E at al. designed and developed circular cam follower assembly for different applications. $\mathrm{Wu} \mathrm{W}$. et al. worked on lubrication between cam and tappet type follower to be used in various applications. Shirzadegan M. et al. presented roller type follower and cam assembly with the help of computer simulation. Alakhramsing S.S. et al. investigated about cam and follower mechanisms lubrication in depth. The authors through light on roller slip, lubricating oil film thickness and friction between roller pin and contact surfaces.Yu I Podgornyj et al. defined the motion laws for cam and follower assembly mechanisms.

A huge literature is available on cam and follower mechanisms for Engineers/designers/ researchers but a few for U.G. /P.G. Students and research scholars. Therefore, the aim of present work is to facilitate the U.G., P.G. students and Research Scholars by providing experimental evidence/procedure available to them in their laboratories.

\section{MATERIAL AND METHODOLOGY}

Cam and follower experimental setup available in the Machine Dynamics laboratory of Mechanical Engineering Department is shown in Figure 1, which is a motorized. The cam shaft is connected with motor with the help of coupling. The shaft is supported with the ball bearings at both the ends. The cam is attached towards the free end of the cam shaft with the help of key. The follower reciprocates inside the bushes guide. This follower assembly can be changed as and when needed so for the cam to be used. There is a spring to keep the follower in contact with cam. The complete system is provided to rotate the cam against the follower. A mechanical tachometer and dial indicators are used for recording the experimental readings. The jumping occurs if the cam and follower moves due to the spring load.

Jumping happens when cam rotates at critical speed above certain value. At jumping, the speed is so high that the follower does not follow the cam and we get a sound of different type. Due to the compressive load applied by the spring, at higher speeds, follower moves without following the cam and thus jumping happens. This is the change of speed conditions due to high speeds. In jumping conditions, both the elements namely cam and follower of the cam system swing independently. in this case, follower does not remain in the control of its cam.To observe the phenomenon of jump, use of stethoscope is necessary.

Observations: The jumping phenomenon in cam follower setup is based upon two categories spring length and no load. At any particular time, anyone of the two quantities is kept constant. Digital tachometer is used to measure the rpm. Jumping phenomenon occurs at any certain point or voltage, where after, there is change in sound of striking of follower and cam. At this point time, we take the readings. 


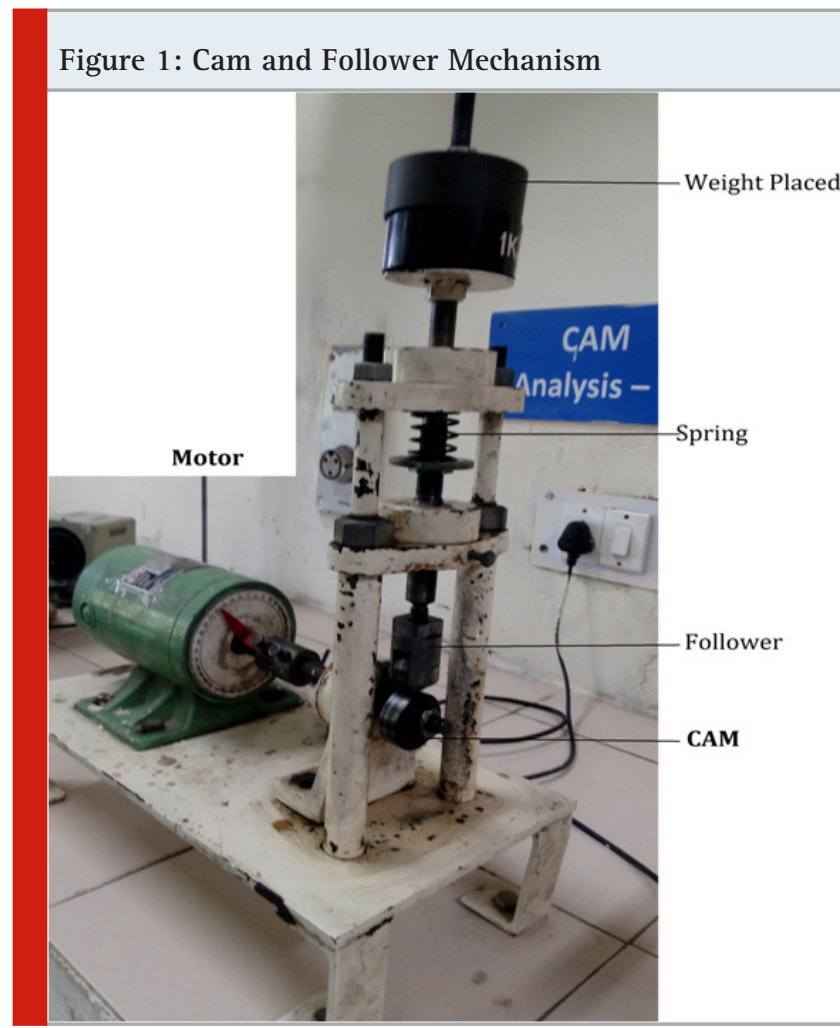

(a) the author noted the jumping with naked eye and calculated the jumping speed with the application of equation (1), that is obtained by equating the upward inertia force and downward retaining force.

\section{$\mathbf{W} \mathbf{r} \omega^{2} / \mathbf{g}=\mathbf{W}+\mathbf{S}$}

(1)

Here , W is the weight placed on the follower assembly, $\mathrm{S}$ is the compressive load applied by the spring, $\omega$ is the angular velocity of cam and $r$ is the minimum radius of the cam.

(b) the author recorded the jumping speed according to the weight placed on the follower assembly keeping the spring load constant. Here, we kept the initial spring compression at a certain level and recorded the jumping speed with the help of mechanical tachometer for different follower weights by adding them successively (shown in Table 1) and plotted the graph of follower weight Vs Jump speed which is shown in Figure 2.

\section{$\omega=(\mathbf{W}+\mathbf{S}) \mathrm{g} /(\mathbf{r} \mathbf{W})$}

(2)

This relation shows that if the follower weight increases, the jump speed goes on decreases.

(c) Now, we record the second set of observations to observe the relation between jumping speed and spring compression by making constant weight on the follower assembly. The author recorded these observations in Table 2 and a graph is drawn in Figure 3 between jumping speed and spring force.
Table 1. Observations of Follower Weight and Jump Speed Keeping Spring Length Constant

\begin{tabular}{|c|c|c|c|}
\hline S N & $\begin{array}{c}\text { W (Weight on } \\
\text { Follower } \\
\text { Assembly) in Kg }\end{array}$ & $\begin{array}{c}\text { N (Jumping } \\
\text { Speed) } \\
\text { in RPM }\end{array}$ & $\begin{array}{c}\text { Spring } \\
\text { Length } \\
\text { in cm }\end{array}$ \\
\hline 1 & 0.5 & 407 & 3.7 \\
\hline 2 & 1.0 & 339 & 3.7 \\
\hline 3 & 1.5 & 270 & 3.7 \\
\hline 4 & 2.0 & 200 & 3.7 \\
\hline 5 & 2.5 & 146 & 3.7 \\
\hline
\end{tabular}

Table 2. Observations of Spring Compression and Jump Speed Keeping Follower Assembly Weight Constant (With No Load Conditions)

\begin{tabular}{|c|c|c|c|}
\hline S N & $\begin{array}{c}\text { W (Weight on } \\
\text { Follower } \\
\text { Assembly) in Kg }\end{array}$ & $\begin{array}{c}\text { L (Spring } \\
\text { Length) } \\
\text { in cm }\end{array}$ & $\begin{array}{c}\text { N } \\
\text { (Jumping } \\
\text { Speed) in RPM }\end{array}$ \\
\hline 1 & 0 & 3.5 & 364 \\
\hline 2 & 0 & 3.3 & 370 \\
\hline 3 & 0 & 3.0 & 397 \\
\hline 4 & 0 & 2.8 & 430 \\
\hline 5 & 0 & 2.5 & 500 \\
\hline
\end{tabular}

Figure 2: Effect of weight on Follower Assembly and Jumping Speed keeping Spring Length Constant.

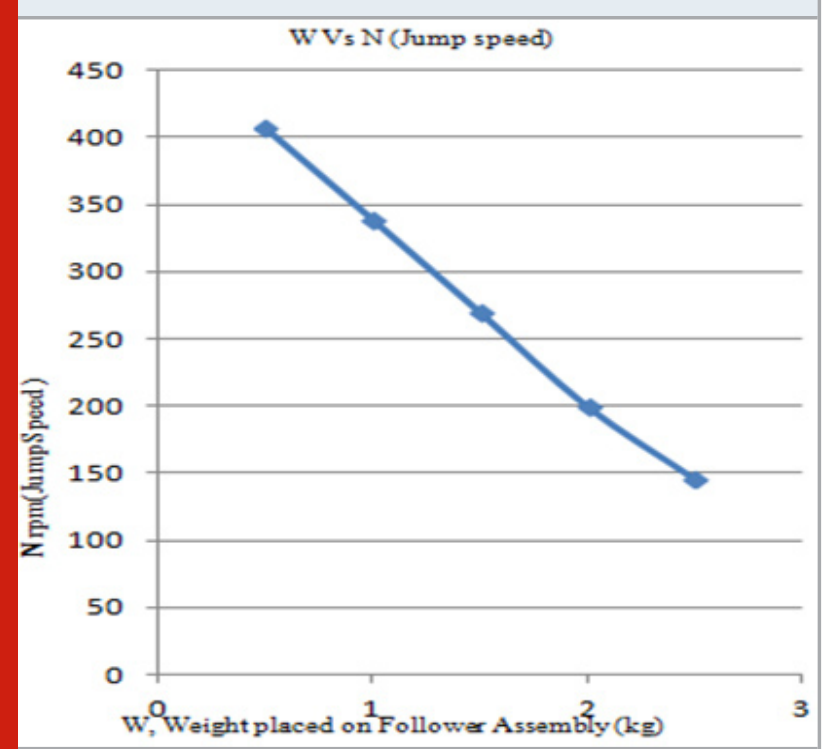

\section{RESULTS AND DISCUSSION}

We observed from Table 1 that the jumping speed is inversely proportional to the weight placed on the follower assembly. It is evident from Figure 2 also that with the increase the load on the follower assembly, the Jump speed decreased with the spring length constant. From Table 2, we see that with no load on follower 
assembly, the jumping speed is inversely proportional to the compression length of spring. It is evident from Figure 3 also that with the decrease of the spring compression length on the follower assembly, the Jump speed is increased while there is no increment in the weight on the follower assembly.

Figure 3: Effect of Spring Length Constant and Jump Speed keeping no weight on Follower Assembly

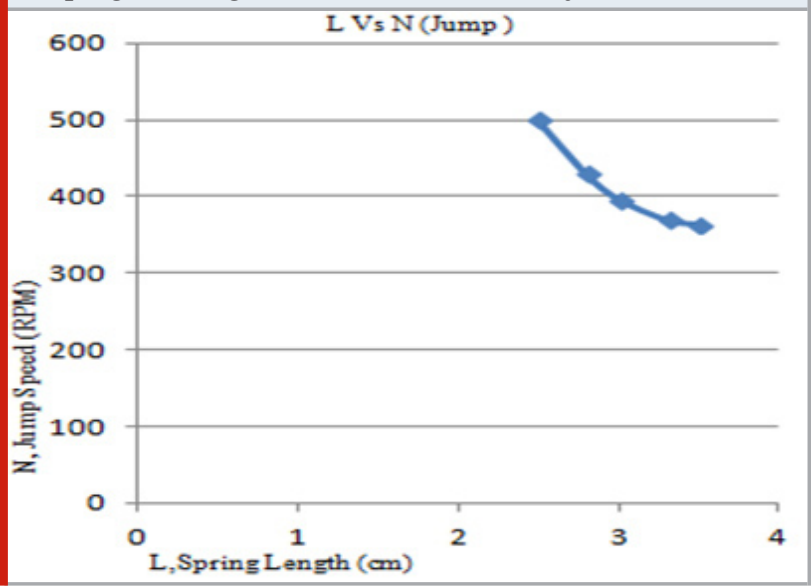

CONCLUSION

At jumping speed, both follower and cam does not obey each other. Jumping is not desirable in any case because the constrained motion rules are violated along with excessive noise, vibrations and hazardous working conditions. We observed that spring stiffness as well as compression of the spring is the key parameters in the cam and follower mechanisms design. If there is no compression in the spring, there will be zero contact between cam and follower and both will separate and follower will have the ability to jump the cam. Therefore, jump is undesirable in cam and follower mechanisms. So, we should always provide sufficient spring force and preload to the cam and follower pair at all the duration to make sure that both cam and follower remain in contact during the entire rotation. This work can be extended in future up to vibration measurement along with the jump speed. The maximum speed of the cam or jump speed along with frequency of vibration should be notified to the designer in the initial stage of cam and follower mechanism design.

\section{ACKNOWLEDGEMENTS}

The author appreciates and is thankful to Prof. Emran Khan, Head, Department of Mechanical Engineering, F/O- Engineering and Technology, Jamia Millia Islamia (A Central University), New Delhi for granting all the facilities along with the permission to work in the Laboratory and all those who participated in the study and helped me to facilitate the research process successfully.

\section{REFERENCES}

A. Cardona et.al., 'Optimal Design of Cams', Multibody
System Dynamics, vol. 1, no. 3, pp. 285-305, 2002. doi: 10.1023/A:1015278213069

A. Rivola et.al., 'Electrodynamic Analysis of the Desmodromic Valve Train of a Racing Motor Bike Engine by Means of a Combined Lumped / Finite Element Model', DIEM-Department of Mechanical Engineering, University of Bologna, vol. 21, pp. 735760, 2007.

Alakhramsing, S.S. et.al., 'A Full numerical solution to the coupled cam-roller and roller-pin contact in heavily loaded cam-roller follower mechanisms', Proc. Inst. Mech. Eng. Part J J. Eng. Tribol. , vol. 232, Issue 10, pp. 1273-1284, 2018.

Alakhramsing, S.S. et.al., 'A Mixed-TEHL Analysis of can-roller contacts considering roller slip: on the influence of roller-pin contact friction', J. Tribol, vol. 141,Issue 6, 015503, 2018.

Alakhramsing, S.S. et.al., 'Lubrication and frictional analysis of cam-roller follower mechanisms', Proc. Inst. Mech. Eng. Part J J. Eng. Tribol. , vol. 232, Issue 3, pp. 347-363, 2018.

AmolAchyutrao Pande, Surendra C. Patel., 'Optimization of a Radial Cam of an I.C. Engine by reducing area of contact with follower', International Journal of Science, Engineering and Technology Research, vol. 4, Issue 9 , pp. 3086-3090, 2015.

Cuilli, E.; Fazzolari, F.; Piccigallo, B., 'Experimental study on circular eccentric cam-follower pairs', Proc. Inst. Mech. Eng. Part J J. Eng. Tribol. , vol. 228, Issue 10, pp. 1088-1098, 2014.

Divya Pandey et.al., 'Analysis and Study of Cam and Follower through ANSYS and Artificial Neural Network', International Journal of Engineering and Science, vol. 4, Issue 7 , pp. 1-8, 2015.

H. D. Desai and V. K. Patel, 'Computer Aided Kinematic and Dynamic Analysis of Cam and Follower', Proceedings of the World Congress on EngineeringLondon, vol. 2, pp. 117-127, 2010.

H. Saito and I. Kimpara, 'Damage Evolution Behavior of CFRP Laminations under post impact fatigue with water absorption Environment', Composite Science and Technology, vol. 69,Issue 6, pp. 847-855, 2009.

Hazim U. Jamali et.al, 'Lubrication Analyses of Cam and Flat-Faced Follower', Lubricants, vol. 7,31, pp. 1-19, 2019. doi:10.3390/lubricants7040031.

J. W. David et.al., 'Optimal Design of High Speed Mechanical Systems', North Carolina State University, Raleigh, Tech. Rep. CRSC-TR97-18, 1997.

Jevzy Zajaczkowski, 'Application of Mathematical Methods to designing a Cam Driven Loom Batten', Fibres and Textiles in Eastern Europe, vol. 13, no. 3 , pp. 70, 2005.

Khin Maung Chin, 'Design and Kinematic Analysis of Cam -Follower System ', GMSARN International conference on sustainable development: Issues and Prospects for the GMS, pp. 12-14, 2008.

Kushwaha, M.; Rahnejat, H., 'Transient 
elastohydrodynamic lubrication of finite line conjuction of cam to follower concentrated contact', J. Phys. D Appl. Phys., vol. 35,no. 21, 2872 ,2002.

Mahesh R. Mali et.al, 'Design Optimization of Cam and Follower of an Internal Combustion Engine for Improving the Engine Efficiency', Modern Mechanical Engineering, vol. 2,pp. 114-119, 2012.doi.org/10.4236/ mme.2012.23014

Mandal, M. and Naskar, T.K., 'Introduction of control points in splines for synthesis of optimizes cam motion program', Mechanism and Machine Theory, vol. 44, pp. 255-271, 2009.

N.S.Patel, 'Modeling, Design and Analysis of Cam and Follower-A Review Paper', International Journal of Studies and Technical Approach, vol. 1, no. 2, pp. 3642, 2015.

Nguyen, M.; Kim, D.J., 'Flexible Cam profile synthesis method using smoothing spline curves ', Mech. Mach. Theory, vol. 42,Issue 7, pp. 825-838, 2007.

R.L. Norton and R.G. Mosier, 'Cam Design and Manufacturing Handbook', Industrial Press, Inc., New York, 2002.

Shailendra Singh, S. Sanyal, 'Deviations in coupler curve due to Hygrothermal Environment in four bar planar mechanism made of neat resin', Discovery Engineering, vol. 4,no 2, pp. 198-207, 2016.

Shailendra Singh, S. Sanyal, 'Kinematic and Dynamic Variations in Cam and Follower made of composite Materials under Hygrothermal Environment', International Journal of Innovative Research in Science, Engineering and Technology, vol. 6,Issue 3, pp. 44204438, 2017.

Shailendra Singh, S. Sanyal, 'Variations in geometry,volume, mass, moment of inertia of link of a four bar mechanism made of neat resin under Hygrothermal Environment', International Journal of Innovative Research in Science, Engineering and Technology (IJIRSET) , vol. 5,Issue 12, pp. 21371-21382, 2016.
Shirzadegan, M. et.al., 'Fully coupled EHL model for simulation of finite length line cam-roller follower contacts', Tribol. Int. , vol. 103,pp. 584-598, 2016.

Shivam S Alakhramsing et.al., 'Lubrication and frictional analysis of cam-follower mechanisms', Proc IMechE Part J: J. Engineering Tribology , vol. 232(3), pp. 347-363, 2018.

T. D. Choi et.al., 'Optimization of Automotive Valve Train Components with Implicit Filtering', Optimization and Engineering, vol. 1, no. 1, pp. 9-27, 2000. Doi: 10.1023/A: 1010071821464

Toedorescu, M. et.al. 'Elastodynamic Transient analysis of a four cylinder valve train system with cam shaft flexibility', Proc. Inst. Mech. Eng. Part K J. Multi-Body Dyn. , vol. 219, Issue 1, pp. 13-25, 2005.

Toedorescu, M. et.al. 'Integrated Tribological analysis within a multi-physics approach to system dynamics', Tribol. Interface Eng. Ser. , vol. 48, pp. 725-737, 2005.

Vela, D. et.al., 'Investigation on cam follower lubricated contact', Proc. Inst. Mech. Eng. Part J J. Eng. Tribol. , vol. 225, Issue 6, pp. 379-392, 2011.

Wang, J.; Venner, C.H.; Lubrecht, A.A., 'Influence of surface waviness on the thermal Elastohydrodynamic Lubrication of an eccentric-Tappet Pair', J.Tribol. , vol. 135, Issue 2, pp. 021001 (11 pages), 2013.

Wu, W.; Wang, J.; Venner, C.H., 'Thermal Elastohydrodynamic Lubrication of an optimized camTappet pair in smooth contact.' J.Tribol. , vol. 138,Issue 2, pp. 021501(14 pages) , 2016.

Yu I Podgornyj et.al.; The Synthesis of Motion Laws for Cam Mechanisms with additional Movement of the Follower',IOP Conf. Series: Earth and environmental science, vol. 378,pp. 1-5, 2019. doi:10.1088/1755/378/1/012025.

Yuan L. Lai et.al., 'Roller Guide Design And Manufacturing for Spatial Cylindrical Cams', World Academy of Science, Engineering and Technology, vol. 38, pp. 109-118, 2008. 